\title{
Obstáculos epistemológicos y cognitivos en el aprendizaje del cálculo diferencial: Una mirada sobre los casos de límites especiales
}

\section{Epistemological and cognitive obstacles in learning of the diferential calculus: A look at the cases of special limits}

\author{
Yesika Rojas-Sandoval ${ }^{1}$ \\ Iván Padilla Escorcia ${ }^{2}$ \\ Salomón David Consuegra Pacheco ${ }^{3}$ \\ Angélica Trujillo Quiroz ${ }^{4}$ \\ Teremy Ortega Tovar ${ }^{5}$ \\ Luz Yineth Rivera Marenco ${ }^{6}$ \\ Yolima Rocha-Fontalvo ${ }^{7}$ \\ Universidad del Atlántico - Institución Universitaria ITSA
}

\footnotetext{
1 Profesora e Investigadora de la Universidad del Atlántico, yesikarojas@mail.uniatlantico.edu.co, https://orcid.org/00000003-0460-2335

2 Profesor e Investigador de la Universidad del Atlántico, iapadilla@mail.uniatlantico.edu.co, https://orcid.org/0000$\underline{0003-1210-3712}$

3 Decano de Facultad de Ciencias, Educación, Artes y Humanidades, sconsuegra@itsa.edu.co, orcid.org/0000-00033638-132X Institución Universitaria ITSA

4 Licenciada en Matemáticas, amtrujillo@mail.uniatlantico.edu.co, https://orcid.org/0000-0003-4917-3271

5 Profesora e Investigadora de la Universidad del Atlántico, ttovarortega@mail.uniatlantico.edu.co, https://orcid. org/0000-0002-7213-242X

$6 \quad$ Profesora e Investigadora de la Universidad del Atlántico, Iyrivera@mail.uniatlantico.edu.co, https://orcid.org/00000003-0714-1423,

$7 \quad$ Profesora e Investigadora de la Universidad del Atlántico, yrocha@mail.uniatlantico.edu.co, https://orcid.org/0000$\underline{0003-2096-7780}$
} 


\section{RESUMEN}

En el proceso de aprendizaje de cualquier tema que sea nuevo para un estudiante se pueden encontrar varios óbices, que emergen por diversos motivos, sea la forma errónea de explicar el tema por parte del profesorado o la permanencia prolongada en ejemplos y/o teorías de baja dificultad, entre otras. Estos obstáculos impiden la construcción de cualquier conocimiento matemático. En particular, es muy importante identificar los obstáculos epistemológicos y cognitivos en el aprendizaje, dado que facilitaría el crecimiento sistemático en la estructuración del conocimiento, y permitiría construir una base fuerte para la construcción del conocimiento. Por lo que se tomará como contenido matemático el tema de límites especiales, que presenta gran dificultad para su aprendizaje en los estudiantes. El trabajo estará enfocado en los obstáculos epistemológicos y cognitivos que presentan los estudiantes en el aprendizaje de los límites especiales, teniendo como interés dar pautas para la aplicación de herramientas que brinden soluciones e identificar dichos obstáculos. Para ello, se estará utilizando como herramienta, la rúbrica, que es una guía para la evaluación del desempeño del estudiante. También se analizará la noción de obstáculos y su origen, buscando llegar a los motivos para la aparición de los mismos.

\section{PALABRAS CLAVE:}

obstáculos cognitivos, obstáculos epistemológico, limites especiales, rubrica.

\section{ABSTRACT}

In the learning process of any subject, which is new for a student, several obstacles may be encountered, these may arise for various reasons such as a wrong way of explaining the subject or prolonged permanence in examples and / or low theories. difficulty, among others. These obstacles prevent the construction of any mathematical knowledge. In particular, it is very important to identify the epistemological and cognitive obstacles in learning, since it would facilitate the systematic growth in the structuring of knowledge, as well as allowing to build a strong base for the construction of knowledge. Therefore, the subject of special limits will be taken as mathematical content, this presents great difficulty for students to learn. The work will be focused on the epistemological and cognitive obstacles that students present in the learning of special limits, with the interest of giving guidelines for the application of tools that provide solutions and identifying said obstacles. To do this, the rubric will be used as a tool, which is a guide for evaluating student performance. The notion of obstacles and their origin will also be analyzed, seeking to arrive at the reasons for their appearance.

\section{KEY WORDS:}

cognitive obstacles, epistemological obstacles, special limits, rubric.

\section{INTRODUCCIÓN}

Es evidente que la enseñanza y aprendizaje de los principios del cálculo es un proceso complejo para el estudiante. Numerosas investigaciones entre las que se destacan, Salinas y Alanís, (2009), Arias (2019), Hernández, Prada y Ramírez (2017) señalan, que si bien se puede enseñar a los estudiantes a realizar de forma mecánica algunos cálculos de derivadas y a resolver algunos problemas estándar, se encuentran grandes dificultades para hacerlos entrar de verdad en el campo del cálculo y hacerlos alcanzar una comprensión satisfactoria de los conceptos y métodos de pensamiento que son el centro de este campo de las matemáticas (Salinas \& Alanís, 2009). Por lo que como objetivo principal se toma la caracterización de los obstáculos epistemológicos y cognitivos sobre la noción de los casos de límites especiales en estudiantes universitarios, para dar inicio se 
identifican las concepciones epistemológicas asociadas a las dificultades que presentan los estudiantes en el concepto de límite luego se hace una examinación de los obstáculos epistemológicos y cognitivos mediante una rúbrica de evaluación adaptada por algunos constructos teóricos en Educación matemática sobre los conceptos básicos en la temática de límites especiales y por último se sintetiza las implicaciones epistemológicas y cognitivas que afectan la comprensión de los casos de límites especiales en estudiantes universitarios.

\section{MARCO TEÓRICO}

\subsection{Obstáculos epistemológicos en el aprendizaje del límite}

Un obstáculo es un apego que impide el avance de la ciencia. En otros términos, el desarrollo del conocimiento, errores, prejuicios, opiniones de los docentes son transmitidos al estudiante y estos se convierten en obstáculos epistemológicos (Bachelard, 1971) Según Bachelard " La noción del obstáculo epistemológico puede ser estudiada en el desarrollo histórico del pensamiento científico y en la práctica de la educación".

Entiéndase por obstáculos epistemológicos las limitaciones o impedimentos que afectan la capacidad de los individuos para construir el conocimiento real o empírico. El individuo entonces se confunde por el efecto que ejercen sobre él algunos factores, lo que hace que los conocimientos científicos no se adquieran de una manera correcta, lo que obviamente afecta su aprendizaje. Esto lo confirma Bachelard al expresar "Frecuentemente me ha chocado el hecho de que los profesores de ciencias aún más que los otros si cabe, no comprendan que no se comprenda" (Bachelard, 1976: 20)

Por otro lado, se tiene a Brousseau (1998) que conceptualiza obstáculo epistemológico acercándose a las causas que conducen a errores: "El error no es solamente el efecto de la ignorancia, la incertidumbre, sino que es el efecto de un conocimiento anterior, que, a pesar de su interés o éxito, ahora se revela falso o simplemente inadecuado". De este modo, al mencionar obstáculo epistemológico, este autor no se refiere necesariamente a conocimientos erróneos; sino a tipos de conocimiento que están obstaculizando la adquisición (construcción) de uno nuevo(Barrantes, 2006).

Además, Duroux (1982) propone una lista de condiciones necesarias para poder calificar de obstáculo a una concepción. Esta lista, con algunas modificaciones introducidas por Brousseau, es la siguiente:

a) Un obstáculo será un conocimiento, una concepción, no una dificultad ni una falta de conocimiento.

b) Este conocimiento produce respuestas adaptadas a un cierto contexto, frecuentemente reencontrado.

c) Pero engendra respuestas falsas fuera de este contexto. Una respuesta correcta y universal exige un punto de vista notablemente diferente.

d) Además, este conocimiento resiste a las contradicciones con las que se le confronta y al establecimiento de un conocimiento mejor. No es suficiente poseer un conocimiento mejor para que el precedente desaparezca (lo que distingue la superación de obstáculos de la acomodación de Piaget). Es pues indispensable identificarlo e incorporar su rechazo en el nuevo saber.

e) Después de tomar conciencia de su inexactitud, el obstáculo continúa manifestándose de forma intempestiva y obstinada. (Brousseau, 1989a, p. 43) (Cid, 2015). Mas aùn, Spagnolo (1996, pág. 81) completa la definición de obstáculo epistemológico, utilizando una interpretación semiótica de los Lenguajes Matemáticos: "El obstáculo epistemológico está relacionado con el pasaje entre el campo semántico significativo 
en una cierta época histórica de la comunidad matemática y el tentativo de la misma de poner a punto un nuevo lenguaje relativo a una cierta clase de problemas. Los objetos matemáticos de los campos semánticos anteriores que podrían servir para la construcción sintáctica (en los fundamentos del nuevo lenguaje), son los obstáculos epistemológicos" Malisani (citado por Cervantes, 2016).

\subsection{Obstáculos cognitivos en el aprendizaje del limite}

Se define a los obstáculos cognitivos como conocimientos que han sido satisfactorios para la resolución de algunos problemas durante algún tiempo, sin embargo, resultan inadecuados y de difícil adaptación al enfrentarse los estudiantes a otros problemas. Por otro lado, interesa destacar lo que indica Tall (1989), en su trabajo "Different Cognitive Obstacles in a Technological Paradigm". Él no hace distinciones entre los obstáculos. Los llama simplemente obstáculos cognitivos, y distingue dos tipos:

Obstáculos basados en la secuencia de un tema, en que afirma que la razón para creer en obstáculos surge fundamentalmente del hecho de que ciertos conceptos tienen un grado de complejidad, por lo que es preciso familiarizarse con ellos en un cierto orden. Por ejemplo, el caso del álgebra, en el que las destrezas operatorias son enseñadas con anterioridad a ideas conceptuales aparentemente más profundas y obstáculos basados sobre casos simples, posiblemente causados por limitar al estudiante a casos simples por un período sustancial de tiempo, antes de pasar a casos más complejos.

En este mismo orden de ideas, Herscovics (1989), se sitúa en un punto de vista esencialmente constructivista e interpreta la noción de obstáculo cognitivo en términos de la teoría piagetiana, señalando que el estudiante se enfrenta a nuevas ideas que no tienen cabida en sus estructuras cognitivas ya existentes, lo que ocasiona que no pueda enfrentarse adecuadamente a la nueva información. Se puede tomar como válido que los obstáculos cognitivos son producto de la experiencia previa de los alumnos y del procesamiento interno de estas experiencias, y que nuestra organización curricular, diseñada para presentar los objetos matemáticos de las formas lógicamente más simples, puede realmente causar obstáculos cognitivos, pero que también surgen obstáculos cognitivos que no tienen que ver con esta organización curricular sino que tienen que ver con otros aspectos, como por ejemplo, la lógica interna de las Matemáticas y en algunos casos con los que hemos denominado en los apartados anteriores, lógica social. (Socas Robayna, 2010)

Otro aporte realizado fue de Brousseau (1983, p.173, citado por Ruiz, 1993) menciona que los obstáculos cognitivos pueden ser generados por diferentes causas: de origen ontogénico, debido a las limitaciones del sujeto en un momento de su desarrollo; de origen didáctico, ligados al sistema de enseñanza en que se encuentran los alumnos y de origen epistemológico, debido a la naturaleza del conocimiento matemático en sí mismo o a la transposición didáctica del saber científico al saber escolar. Un Obstáculo cognitivo de origen epistemológico, tiene las siguientes características: se trata siempre de un conocimiento y no de una ausencia de conocimiento; este conocimiento permite al alumno producir respuestas correctas en determinados problemas o dominio de problemas; este mismo conocimiento engendra respuestas (Cecilia \& Emilse, 2015)

\subsection{Noción del Concepto de Límites}

La comunidad matemática dispone hoy de una caracterización formal del concepto de límites. Respecto a este concepto, las definiciones propuestas por Weirstrass y Cauchy respectivamente, mantienen, aún hoy, su vigencia. La caracterización lógico-formal del límite y la derivada ha sido una de los 
fundamentos en ciertos modelos de enseñanza. Pero tal como lo muestran los resultados de investigaciones didácticas desarrolladas, las dificultades que presentan los estudiantes son fuertes y resistentes (Fernández, 2015).

Si bien es cierto, el concepto de "límite" ocupa una posición central en el campo conceptual del cálculo y su complejidad resulta ser fuente de dificultades tanto en la enseñanza como en el aprendizaje. Según Medina (2001) Primero por su carácter estructural que lo constituye el eje central y concepto básico sobre el cual se construye la estructura del Cálculo diferencial e integral y otros conceptos de otras ramas de la matemática; también por su carácter instrumental como herramienta para la solución de problemas tanto al interior de las matemáticas como de ciencias aplicadas como la Física, la Ingeniería y finalmente, como objeto matemático que se gesta en diferentes con textos: geométrico, aritmético, métrico, topológico y asociado a otros objetos matemáticos.

En efecto, en la Educación Superiorgeneralmente se introduce a través de la definición formal o de las técnicas algorítmicas para su cálculo. Investigaciones en Educación Matemática han evidenciado que la definición de un concepto no garantiza la comprensión del concepto; una cosa es la imagen del concepto y otra la imagen de la definición que se forman los estudiantes, Tall y Vinner (1981, citado por Medina y Rojas, 2015). La definición formal da precisión y rigor matemático, pero, encapsula las situaciones y procesos que le dan sentido al concepto, ocultando su significación y complejidad. Al respecto, la noción de límite en realidad se encuentra implícita, y se ve una evolución de su estatus, pasando de ser una noción que ni siquiera se explicita como útil al ser, con los infinitésimos y las razones primeras y últimas de Newton, una herramienta para resolver problemas. Ahora bien, esta idea de límite como aproximación sin más no basta. Por una parte, la aproximación tiene que ser indefinida, es decir, tiene que existir la posibilidad de tomar aproximaciones cada vez mejores, cosa que se consigue en todos los métodos revisados, pero hasta Newton esta posibilidad no se plasma claramente en el hecho de que los objetos se han de aproximar "más que cualquier diferencia dada", lo cual implica que el límite debe ser la mejor de todas las aproximaciones posibles.

Definición: Sea $f$ una función y a un número real, el número $L$ es el límite de la función $f$ en el punto a, $y$ se escribe (se lee límite de $f(x)$ cuando $x$ tiende a es $L$ ), si cuando $x$ tiende a, siendo distinto de a, sus imágenes, $f(x)$, tienden a $L$.

\section{METODOLOGÍA}

\subsection{Diseño y metodología de investigación}

Este trabajo está enfocado en la investigación cualitativa, puesto que el objetivo es examinar los obstáculos epistemológicos y cognitivos que se presentan en el aprendizaje de límites especiales, debido a que según Hernández Sampieri (2014) las investigaciones cualitativas se basan en explorar y describir datos no estandarizados ni predeterminados, utiliza técnicas para recolectar datos, como la observación no estructurada, discusión en grupo, evaluación de experiencias personales; para recolectar datos acerca de fenómenos, temas o situaciones delicadas o que son difíciles de discutir o describir; también cuando los participantes no son muy elocuentes, articulados o descriptivos. Esta investigación se desarrolla con el diseño de estudio de casos, por lo que este diseño se caracteriza por precisar de un proceso de búsqueda e indagación, así como el análisis sistemático de uno o varios casos. Para ser más exactos, por caso se entiende todas aquellas circunstancias, situaciones o fenómenos únicos de los que se requiere más información o merecen algún tipo de interés dentro del mundo de la investigación. Para Stake (citado por Álvarez, (2012)) es: "El 
estudio de la particularidad y de la complejidad de un caso singular, para llegar a comprender su actividad en circunstancias importantes" Io que sugiere es que con este diseño se permite encontrar detalles específicos y descripciones sobre cómo el objeto de estudio se ve afectado. Por lo que tomando la clasificación de Pérez Serrano y Martínez Bonafé (citado por Álvarez (2012)) para la metodología investigación mediante el estudio de casos se distinguen las siguientes series de fases:

Fase preactiva: En esta fase se utiliza la prueba diagnóstica, necesaria para la obtención de información que permita analizar los obstáculos epistemológicos y cognitivos que reflejan los estudiantes sobre la noción de los casos de límites especiales.

Fase Interactiva: Luego del análisis de la información recogida en la fase anterior se procede al análisis de un cuestionario estructurado dirigido a los estudiantes con relación a los procedimientos que tuvieron que realizar en la prueba diagnóstica aplicada inicialmente, esto es para detallar los resultados que se han obtenido a partir de la fase anterior sobre el problema estudiado, es decir los obstáculos epistemológicos y cognitivos que presentan en la noción de los casos de límites especiales.

Fase Postactiva: Esta fase implica la elaboración de una rúbrica de evaluación donde se tiene en cuenta los constructos teóricos en educación matemática sobre los conceptos básicos en la temática de límites especiales que infieren acerca de los obstáculos epistemológicos y cognitivos para poder delimitar la perspectiva con la que se inició la investigación con el fin de determinar aquellos obstáculos que afectan la comprensión de los casos de límites especiales.

\subsection{Población y muestra}

Para la aplicación de esta investigación, se escogieron los estudiantes que hayan cursado la asignatura de cálculo diferencial de una y varias variables de la facultad de educación del programa de pregrado de licenciatura en matemáticas pertenecientes a la Universidad del Atlántico sede norte ubicada en el $\mathrm{Km} 7$ Antigua vía Puerto Colombia de la ciudad de Barranquilla, Atlántico. Teniendo en cuenta el diseño de estudio de casos, se realiza la selección de una muestra, considerando que Samaja (citado por Ruth Kazez (2009)) afirma que es posible realizar un estudio exploratorio tomando pocos individuos de un determinado nivel de la matriz de datos y sobre grandes cantidades de un nivel inferior de agregación. Por lo anterior se procede a escoger tres estudiantes a los cuales como premisa para participar es que hayan cursado la asignatura cálculo diferencial de una y varias variables de acuerdo al de acuerdo con el nuevo pensum de licenciatura en matemáticas. Para su elección se tuvo en cuenta el tipo de muestra intencional, debido a que este tipo de muestreo se caracteriza por un esfuerzo deliberado de obtener muestras "representativas" mediante la inclusión en la muestra de grupos supuestamente típicos.

\subsection{Técnica e Instrumentos}

Para Hernández Sampieri (2014) "un instrumento de medición adecuado es aquel que registra datos observables que representan verdaderamente los conceptos o las variables que el investigador tiene en mente". Por lo que se definen las técnicas e instrumentos fundamentales para el cumplimiento de los objetivos de esta investigación y la finalidad de cada uno de ellos, estos son: Prueba diagnóstica que para Santos (1995:166), afirma que a través de la evaluación diagnóstica se puede saber cuál es el estado cognoscitivo y actitudinal de los estudiantes. Permite ajustar la acción a las características de los estudiantes. La prueba consta en total de 10 preguntas, en la cual los interrogantes 1, 2, 3 y 4 van apuntados hacia 
las nociones que tienen acerca de limite, de tal manera que se logre saber hasta qué punto manejan ese cocimiento, las preguntas $5,6,7$, 8,9 y 10 apuntan a la resolución de problemas en donde deben hacer uso de sus conocimiento respecto al tema y de qué modo proceden para llegar a la solución de los mismos. Sera realizada de manera individual y virtual a los estudiantes seleccionados por medio de la muestra en cálculo I de la facultad de educación del programa de pregrado de licenciatura en matemáticas pertenecientes a la Universidad del Atlántico, la cual tendrá el tiempo límite de 120 minutos para ser desarrollada. Un Cuestionario estructurado a estudiantes en el que consiste en un conjunto de preguntas, normalmente de varios tipos, sobre hechos y aspectos que interesan en una investigación o evaluación, y puede ser aplicado en formas variadas; Su característica singular radica en que la información solicitada a los sujetos es menos profunda e impersonal. Al mismo tiempo, permite consultar a una gran cantidad de personas de una manera rápida y económica (Garcia Muñoz, 2003). Por medio del cuestionario se busca obtener información de los estudiantes que corrobore los resultados de la prueba diagnóstica, para poder determinar aquellos obstáculos presentes en el aprendizaje de límites especiales. Este cuestionario cuenta con 10 preguntas, en donde las dos primeras se relacionan con las nociones de límite para saber los conocimientos que tienen con respecto al tema para comparar lo que hicieron en la prueba, la tercera, la cuarta y la quinta apuntan a la resolución de problemas que permita saber la forma en que se desenvuelven y que tipo de dificultades presentan al momento de resolverlas; por otro las cinco últimas, son preguntas con respecto al tipo de motivación o desmotivación que presentan los estudiantes con respecto al tema de límite. Esta técnica será desarrollada por los estudiantes seleccionados en la muestra de forma escrita y contaran con 30 minutos. Y por último se realiza una Rúbrica que para Fernández March (2010) las rúbricas son «guías de puntuación usadas en la evaluación del desempeño de los estudiantes que describen las características específicas de un producto, proyecto o tarea en varios niveles de rendimiento, con el fin de clarificar lo que se espera del trabajo del alumno, de valorar su ejecución y de facilitar la proporción de feedback. Por lo que esta técnica es una herramienta de valoración utilizada para reflejar el grado de cumplimiento de una actividad o trabajo. Se presenta como una pauta o tabla de doble entrada que permite unir y relacionar criterios de evaluación, niveles de logro y descriptores.

\section{ANÁLISIS DE RESULTADO}

En la tabla 1 se muestra la composición de la rúbrica que evaluativa que se utilizó para esta investigación 
Tabla 1: Rubrica de evaluación

\begin{tabular}{|c|c|c|c|c|c|}
\hline & \multicolumn{2}{|l|}{ TEMA } & \multicolumn{3}{|c|}{ LIMITES ESPECIALES } \\
\hline & \multicolumn{2}{|l|}{ ESTUDIANTE } & \multirow[b]{2}{*}{ Bueno (2Puntos) } & \multirow[b]{2}{*}{$\begin{array}{l}\text { Deficiente } \\
\text { (1 Puntos) }\end{array}$} & \multirow[b]{2}{*}{$\begin{array}{l}\text { No lo hizo (0- } \\
\text { Puntos) }\end{array}$} \\
\hline & $\begin{array}{l}\text { Criterios de } \\
\text { evaluación/ } \\
\text { Niveles de } \\
\text { expectativa }\end{array}$ & $\begin{array}{l}\text { Excelente (3 } \\
\text { Puntos) }\end{array}$ & & & \\
\hline \multirow{5}{*}{$\begin{array}{l}\text { Obstáculo } \\
\text { Epistemológico }\end{array}$} & $\begin{array}{l}\text { EXPERIENCIA } \\
\text { BASICAO } \\
\text { CONOCIMIENTO } \\
\text { PREVIO }\end{array}$ & $\begin{array}{l}\text { Demuestra } \\
\text { noción amplia } \\
\text { del tema }\end{array}$ & $\begin{array}{l}\text { Demuestra } \\
\text { noción básica del } \\
\text { tema }\end{array}$ & $\begin{array}{l}\text { No demuestra } \\
\text { mucho } \\
\text { entendimiento. }\end{array}$ & $\begin{array}{l}\text { Desconoce } \\
\text { completamente } \\
\text { el tema a } \\
\text { abordar }\end{array}$ \\
\hline & $\begin{array}{l}\text { OBSTACULO } \\
\text { VERBAL }\end{array}$ & $\begin{array}{l}\text { Mediante las } \\
\text { imágenes } \\
\text { o palabras } \\
\text { identifica y } \\
\text { explica a la } \\
\text { perfección lo que } \\
\text { se requiere }\end{array}$ & $\begin{array}{l}\text { Mediante las } \\
\text { imágenes } \\
\text { o palabras } \\
\text { identifica y logra } \\
\text { mediante sus } \\
\text { palabras explicar } \\
\text { los conceptos }\end{array}$ & $\begin{array}{l}\text { Mediante las } \\
\text { imágenes } \\
\text { o palabras } \\
\text { muestra leve } \\
\text { entendimiento }\end{array}$ & $\begin{array}{l}\text { No logra } \\
\text { identificar } \\
\text { Mediante las } \\
\text { imágenes o } \\
\text { palabras }\end{array}$ \\
\hline & $\begin{array}{l}\text { CONOCIMIENTO } \\
\text { GENERAL }\end{array}$ & $\begin{array}{l}\text { Demuestra total } \\
\text { entendimiento de } \\
\text { los conceptos. }\end{array}$ & $\begin{array}{l}\text { Algunos } \\
\text { conceptos no } \\
\text { se tienen muy } \\
\text { claros. }\end{array}$ & $\begin{array}{l}\text { No demuestra } \\
\text { mucho } \\
\text { entendimiento. }\end{array}$ & $\begin{array}{l}\text { Desconoce } \\
\text { completamente } \\
\text { lo que está } \\
\text { realizando. }\end{array}$ \\
\hline & $\begin{array}{l}\text { OBSTACULO } \\
\text { ANIMISTA }\end{array}$ & $\begin{array}{l}\text { Sabe interpretar } \\
\text { correctamente } \\
\text { para expresar } \\
\text { el concepto } \\
\text { y resalta las } \\
\text { características } \\
\text { más relevantes. }\end{array}$ & $\begin{array}{l}\text { Interpreta } \\
\text { el concepto } \\
\text { y resalta } \\
\text { algunas las } \\
\text { características } \\
\text { más relevantes }\end{array}$ & $\begin{array}{l}\text { Tiene vacíos } \\
\text { a la hora de } \\
\text { interpretar el } \\
\text { concepto y no } \\
\text { logra resaltar la } \\
\text { características }\end{array}$ & $\begin{array}{l}\text { No interpreta } \\
\text { adecuadamente } \\
\text { el concepto y } \\
\text { no resalta la } \\
\text { características }\end{array}$ \\
\hline & $\begin{array}{l}\text { CONOCIMIENTO } \\
\text { PRAGMÁTICO Y } \\
\text { UTILITARIO }\end{array}$ & $\begin{array}{l}\text { Detalla los } \\
\text { aspectos } \\
\text { importantes } \\
\text { sin saltar ni } \\
\text { desechar lo } \\
\text { necesario }\end{array}$ & $\begin{array}{l}\text { Logra detallar } \\
\text { con sus palabras } \\
\text { los conceptos }\end{array}$ & $\begin{array}{l}\text { Sus conceptos } \\
\text { no difieren de } \\
\text { una mayor } \\
\text { profundidad }\end{array}$ & $\begin{array}{l}\text { No logra detallar } \\
\text { ni mencionar } \\
\text { ningún aspecto } \\
\text { necesario del } \\
\text { concepto }\end{array}$ \\
\hline \multirow[b]{2}{*}{$\begin{array}{l}\text { Obstáculo } \\
\text { Cognitivo }\end{array}$} & $\begin{array}{l}\text { OBSTACULO } \\
\text { BASADO EN LA } \\
\text { SECUENCIA DE } \\
\text { UN TEMA }\end{array}$ & $\begin{array}{l}\text { Supera la } \\
\text { secuencia de } \\
\text { los temas sin } \\
\text { problema }\end{array}$ & $\begin{array}{l}\text { Logra superar de } \\
\text { manera óptima } \\
\text { los temas }\end{array}$ & $\begin{array}{l}\text { Sus respuestas } \\
\text { no difieren de } \\
\text { manera óptima } \\
\text { los temas }\end{array}$ & $\begin{array}{l}\text { no logra superar } \\
\text { de manera } \\
\text { efectiva a los } \\
\text { siguientes temas }\end{array}$ \\
\hline & $\begin{array}{l}\text { OBSTACULOS } \\
\text { BASADOS } \\
\text { SOBRE CASOS } \\
\text { SIMPLES }\end{array}$ & $\begin{array}{l}\text { Avanza sin } \\
\text { problema alguno } \\
\text { debido a que } \\
\text { logra identificar } \\
\text { lo que necesita } \\
\text { en cada punto }\end{array}$ & $\begin{array}{l}\text { Logra avanzar } \\
\text { a medida que } \\
\text { se le presenta } \\
\text { una situación } \\
\text { diferente }\end{array}$ & $\begin{array}{l}\text { El avance } \\
\text { que obtiene } \\
\text { no demuestra } \\
\text { resultados } \\
\text { efectivos }\end{array}$ & $\begin{array}{l}\text { Demuestra } \\
\text { estancamiento } \\
\text { en un tema y no } \\
\text { logra avanzar }\end{array}$ \\
\hline
\end{tabular}

Fuente: autores 
A continuación, se detalla cada uno de los apartados de dicha rúbrica

\section{OBSTÁCULOS EPISTEMOLÓGICOS}

De acuerdo a Bachelard (1976) se dan cinco obstáculos principales a saber:

La experiencia básica o conocimientos previos: Los individuos antes de iniciar cualquier estudio, tienen un conjunto de ideas muy propias acerca de cómo y el porqué de las cosas son como son. Estas ideas pueden ejercer una potente influencia que puede limitar el proceso de aprendizaje.

El obstáculo verbal: Se presenta cuando mediante una que son los que realmente permiten exponer con claridad y exactitud los caracteres que permiten distinguirlos $y$ conceptuarlos correctamente sola palabra o una imagen se quiere explicar un concepto.

- $\quad$ El peligro de la explicación por la utilidad: El utilitarismo plantea una serie de problemas a la hora de definir un término, porque se tiende a reducir y sintetizar conceptos a través de la utilidad o beneficio.
- $\quad$ El conocimiento general: Al explicar mediante el uso de generalizaciones un concepto, se cae, en la mayoría de las veces, en equivocaciones, porque los conceptos se vuelven vagos, e indefinidos, ya que se dan definiciones demasiado amplias para describir un hecho o fenómeno y se deja de lado aspectos esenciales, los detalles • El obstáculo animista: tienden a explicar ciertos fenómenos haciendo analogías con naturaleza animada

\section{OBSTÁCULOS COGNITIVOS}

Tall D. (1989) Establece dos tipos de obstáculos cognitivos:

- Obstáculos basados en la secuencia de un tema: ciertos conceptos tienen un grado de complejidad, por lo que es preciso familiarizarse con ellos en un cierto orden

- Obstáculos basados sobre casos simples: causados por limitar al estudiante a casos simples por un período sustancial de tiempo, antes de pasar a casos más complejos.

A continuación se muestra en la tabla 2 los resultados de los estudiantes que se sometieron a la prueba

Tabla 2: Resultados de rubrica evaluativa

Resultrado de Rubrica evaluativa pera estnudiante I

\begin{tabular}{|c|c|c|c|c|c|c|}
\hline \multicolumn{5}{|c|}{ Obticus telatengleges } & \multicolumn{2}{|c|}{ oesticuocopitive } \\
\hline 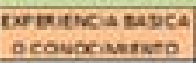 & ostatuovenas & $\begin{array}{c}\text { conooutionte } \\
\text { erumpl }\end{array}$ & $\begin{array}{l}\text { Cestacule } \\
\text { shivarta }\end{array}$ & $\begin{array}{l}\text { cohocishovis } \\
\text { macmelines r }\end{array}$ & 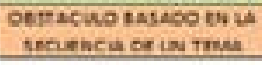 & 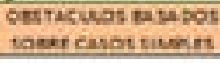 \\
\hline tutvo & evicenti & Dove & sericents & opicente & weroturt & ovisentt \\
\hline
\end{tabular}

Resultado de Rubrica evaluartiva para estudiante 2

\begin{tabular}{|c|c|c|c|c|c|c|}
\hline \multicolumn{5}{|c|}{ 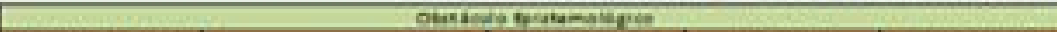 } & \multicolumn{2}{|c|}{ opwancerane } \\
\hline 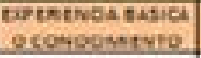 & onstsok o veteas & 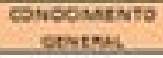 & $\begin{array}{l}\text { pesfacuse } \\
\text { Acturste }\end{array}$ & $\begin{array}{l}\text { CONSENTENo } \\
\text { magnitroir }\end{array}$ & 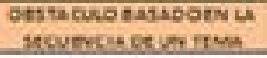 & 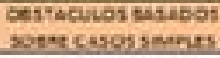 \\
\hline suno & sevibuts & nutho & sencinte & bubtutt & stretsin & NoLO -2as \\
\hline
\end{tabular}

Resultrado de Rubrica evaluariva para estundianire 3

\begin{tabular}{|c|c|c|c|c|c|c|}
\hline \multicolumn{5}{|c|}{ Obetsedolipitinosich } & \multicolumn{2}{|c|}{ ostacio cornitio } \\
\hline 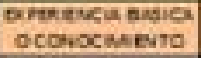 & cestrand veteas & $\begin{array}{l}\text { CONoONENT } \\
\text { anes }\end{array}$ & $\begin{array}{l}\text { Ceneove } \\
\text { Avivista }\end{array}$ & $\begin{array}{l}\text { conocunbito } \\
\text { enucmincor }\end{array}$ & 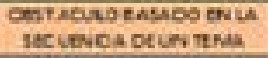 & 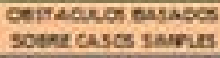 \\
\hline seretwit & sthetveft & tuess & strontt & stheturt & seisfit & NSGU \\
\hline
\end{tabular}

\subsection{Triangulación de información}

La triangulación es necesaria para afrontar el objeto de investigación desde prismas diferentes, especialmente cuando el tema de estudio es amplio y se ve influido por diversas causas, 
las cuales pueden esta interrelacionadas o no. Lo práctico de la triangulación del grupo, no viene dado únicamente por su carácter multidisciplinar, que enriquece el diseño de la herramienta para la obtención de información (cualitativa y/o cuantitativa), sino que además es factible el análisis conjunto y sincrónico de los datos obtenidos (Alzás García, 2017).

A continuación se presenta la triangulación de información con respecto a los datos obtenidos mediante la prueba diagnóstica, el cuestionario estructurado y la rúbrica. Tabla 3.

Tabla 3: Triangulación de información: Prueba diagnóstica, cuestionario estructurado y la rúbrica

\begin{tabular}{|c|c|c|c|c|c|}
\hline $\begin{array}{l}\text { CATEGORIA } \\
\text { DE } \\
\text { ANALISIS }\end{array}$ & SUBCATEGORIA & $\begin{array}{l}\text { PRUEBA } \\
\text { DIAGNOSTOCA }\end{array}$ & $\begin{array}{l}\text { CUESTIONARIO } \\
\text { ESTRUCTURADO }\end{array}$ & RUBRICA & TRIANGULACION \\
\hline 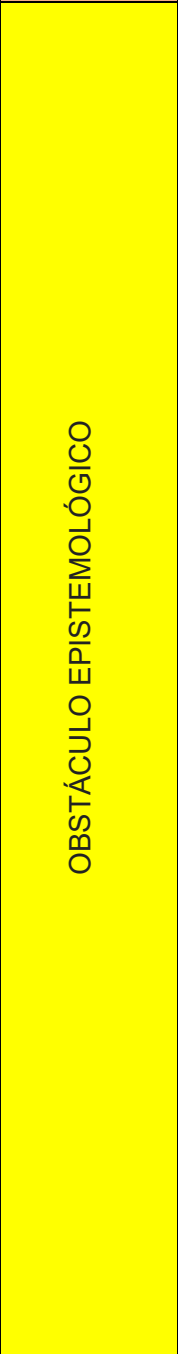 & $\begin{array}{l}\text { EXPERIENCIA } \\
\text { BASICA O } \\
\text { CONOCIMIENTO } \\
\text { PREVIO }\end{array}$ & $\begin{array}{l}\text { Los } \\
\text { estudiantes } \\
\text { denuestan } \\
\text { noción básica } \\
\text { en cuanto a los } \\
\text { conceptos de } \\
\text { limite en ítems } \\
\text { relacionados } \\
\text { con la } \\
\text { experiencia } \\
\text { básica o } \\
\text { conocimiento } \\
\text { previo debido a } \\
\text { que tienen un } \\
\text { conjunto de } \\
\text { ideas acerca } \\
\text { de cómo y el } \\
\text { porqué del } \\
\text { concepto sin } \\
\text { embargo estos } \\
\text { conocimientos } \\
\text { previos } \\
\text { carecen bases } \\
\text { amplias lo cual } \\
\text { de aprendizaje }\end{array}$ & $\begin{array}{l}\text { Los estudiantes } \\
\text { manifiestan que } \\
\text { debido a la falta de } \\
\text { una base sólida de } \\
\text { conocimientos } \\
\text { previos con } \\
\text { respecto al límite se } \\
\text { les dificulta dar } \\
\text { solución a algunos } \\
\text { de los ítems } \\
\text { propuestos }\end{array}$ & $\begin{array}{l}\text { De acuerdo a las } \\
\text { respuestas en la } \\
\text { prueba diagnóstica } \\
\text { donde se determinan } \\
\text { los niveles de } \\
\text { experiencia que } \\
\text { evalúa en que nivel se } \\
\text { encuentra cada } \\
\text { estudiante para la } \\
\text { superación de este } \\
\text { obstaculillos } \\
\text { resultados muestran } \\
\text { que aunque no se } \\
\text { arrojó la superación } \\
\text { total del obstáculo } \\
\text { muestran avance } \\
\text { significativo que } \\
\text { influyen el proceso de } \\
\text { aprendizaje }\end{array}$ & $\begin{array}{l}\text { Los datos } \\
\text { muestran similitud } \\
\text { en los análisis y } \\
\text { es notable la } \\
\text { relación a las } \\
\text { dificultades que } \\
\text { presentan los } \\
\text { estudiantes en la } \\
\text { superación del } \\
\text { obsta. } \\
\text { Epistemológico } \\
\text { de experiencia } \\
\text { básica o } \\
\text { conocimiento } \\
\text { previo con } \\
\text { respecto al tema } \\
\text { de limite. Los } \\
\text { resultados } \\
\text { tienden a la } \\
\text { misma } \\
\text { información por lo } \\
\text { que influye en la } \\
\text { necesidad de } \\
\text { reforzar los } \\
\text { métodos de } \\
\text { enseñanza desde } \\
\text { temprano }\end{array}$ \\
\hline
\end{tabular}




\begin{tabular}{|c|c|c|c|c|}
\hline $\begin{array}{l}\text { OBSTACULO } \\
\text { VERBAL }\end{array}$ & $\begin{array}{l}\text { Los estudiantes } \\
\text { mediante las } \\
\text { imágenes o } \\
\text { palabras } \\
\text { muestran leve } \\
\text { entendimiento } \\
\text { o en algún } \\
\text { caso no logran } \\
\text { identificar } \\
\text { editan } \\
\text { imágenes o } \\
\text { palabras lo } \\
\text { requerido con } \\
\text { respecto al } \\
\text { tema de limite } \\
\text { en ítems } \\
\text { relacionado en } \\
\text { este obsta. } \\
\text { Epistemológico }\end{array}$ & $\begin{array}{l}\text { Los estudiantes } \\
\text { manifiestan que no } \\
\text { logran ver a simple } \\
\text { vista lo que se } \\
\text { necesita para } \\
\text { identificar y explicar } \\
\text { conceptos de limite } \\
\text { mediante imágenes } \\
\text { o palabras }\end{array}$ & $\begin{array}{l}\text { De acuerdo a las } \\
\text { respuestas en la } \\
\text { prueba diagnóstica } \\
\text { donde se determinan } \\
\text { los niveles de } \\
\text { experiencia que } \\
\text { evalúa en que nivel se } \\
\text { encuentra cada } \\
\text { estudiante para la } \\
\text { superación de este } \\
\text { obstaculillos } \\
\text { resultados se } \\
\text { muestran poco } \\
\text { favorables para } \\
\text { explicar un concepto y } \\
\text { dar respuesta los ítem } \\
\text { propuestos mediante } \\
\text { imágenes o palabras }\end{array}$ & $\begin{array}{l}\text { Los datos } \\
\text { muestran similitud } \\
\text { en los análisis y } \\
\text { es notable la } \\
\text { relación a las } \\
\text { dificultades que } \\
\text { presentan los } \\
\text { estudiantes en la } \\
\text { superación del } \\
\text { obstáculo. } \\
\text { Epistemológico } \\
\text { verbal con } \\
\text { respecto al tema } \\
\text { de limite. Los } \\
\text { resultados } \\
\text { tienden a la } \\
\text { misma } \\
\text { información por lo } \\
\text { que influye en la } \\
\text { necesidad de } \\
\text { reforzar los } \\
\text { métodos } \\
\text { didácticos de } \\
\text { enseñanza desde } \\
\text { temprano }\end{array}$ \\
\hline $\begin{array}{l}\text { CONOCIMIENTO } \\
\text { GENERAL }\end{array}$ & $\begin{array}{l}\text { Los estudiantes } \\
\text { al explicar el } \\
\text { uso de } \\
\text { generalizacione } \\
\text { s muestran que } \\
\text { algunos } \\
\text { concepto no se } \\
\text { tienen muy } \\
\text { claros por lo } \\
\text { que tienden a } \\
\text { quitaciones, lo } \\
\text { que da como }\end{array}$ & $\begin{array}{l}\text { Los estudiantes } \\
\text { ratifican sus } \\
\text { respuestas dando } \\
\text { explicaciones } \\
\text { demasiado amplias } \\
\text { y dejan de lado los } \\
\text { detalles que } \\
\text { realmente permiten } \\
\text { exponer con } \\
\text { claridad y exactitud } \\
\text { los conceptos de }\end{array}$ & $\begin{array}{l}\text { De acuerdo a las } \\
\text { respuestas en la } \\
\text { prueba diagnóstica } \\
\text { donde se determinan } \\
\text { los niveles de } \\
\text { experiencia que } \\
\text { evalúa en que nivel se } \\
\text { encuentra cada } \\
\text { estudiante para la } \\
\text { superación de este } \\
\text { obstaculillos } \\
\text { resultados se }\end{array}$ & $\begin{array}{l}\text { Los datos } \\
\text { muestran similitud } \\
\text { en los análisis y } \\
\text { es notable la } \\
\text { relación a las } \\
\text { dificultades que } \\
\text { presentan los } \\
\text { estudiantes en la } \\
\text { superación del } \\
\text { obsta. } \\
\text { Epistemológico } \\
\text { de consciente }\end{array}$ \\
\hline
\end{tabular}




\begin{tabular}{|c|c|c|c|c|c|}
\hline \multirow{2}{*}{ 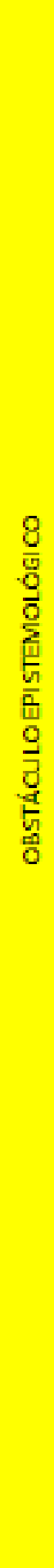 } & & $\begin{array}{l}\text { resultado } \\
\text { respuestas } \\
\text { vagas e } \\
\text { indefinidas en } \\
\text { los ítems } \\
\text { relacionados } \\
\text { con el } \\
\text { conocimiento } \\
\text { general del } \\
\text { tema de limites }\end{array}$ & \begin{tabular}{|l} 
limite \\
correctamente
\end{tabular} & $\begin{array}{l}\text { muestran que aunque } \\
\text { no se tiene total } \\
\text { entendimiento del } \\
\text { concepto de limite } \\
\text { logran un nivel alto } \\
\text { para la superación del } \\
\text { obstáculo }\end{array}$ & $\begin{array}{l}\text { general con } \\
\text { respecto al tema } \\
\text { de limite. Los } \\
\text { resultados } \\
\text { tienden a la } \\
\text { misma } \\
\text { información por lo } \\
\text { que influye en la } \\
\text { necesidad de } \\
\text { continuar } \\
\text { mejorando el } \\
\text { modo en el que } \\
\text { se dan la } \\
\text { explicación del } \\
\text { tema para } \\
\text { mejorar el } \\
\text { proceso de } \\
\text { aprendizaje }\end{array}$ \\
\hline & $\begin{array}{l}\text { OBSTACULO } \\
\text { ANIMISTA }\end{array}$ & $\begin{array}{l}\text { Los estudiantes } \\
\text { demuestran } \\
\text { vacíos a la } \\
\text { hora de } \\
\text { interpretar } \\
\text { adecuadament } \\
\text { e el concepto } \\
\text { de límite para } \\
\text { dar solución a } \\
\text { ítems } \\
\text { relacionados } \\
\text { en la prueba } \\
\text { diagnóstica } \\
\text { debido a que } \\
\text { no resaltan } \\
\text { características } \\
\text { necesarias }\end{array}$ & $\begin{array}{l}\text { Los estudiantes } \\
\text { corroboran con sus } \\
\text { respuestas los } \\
\text { vacíos presentes en } \\
\text { la interpretación del } \\
\text { concepto de limite } \\
\text { puesto que no } \\
\text { logran explicar } \\
\text { fenómenos para la } \\
\text { superación del } \\
\text { obstáculo }\end{array}$ & $\begin{array}{l}\text { De acuerdo a las } \\
\text { respuestas en la } \\
\text { prueba diagnóstica } \\
\text { donde se determinan } \\
\text { los niveles de } \\
\text { experiencia que } \\
\text { evalúa en que nivel se } \\
\text { encuentra cada } \\
\text { estudiante para la } \\
\text { superación de este } \\
\text { obstaculillos } \\
\text { resultados son poco } \\
\text { favorables puesto que } \\
\text { se tomaron en cuenta } \\
\text { cada respuesta dada } \\
\text { en la prueba } \\
\text { diagnóstica que } \\
\text { demuestra las bases } \\
\text { poco solidas del }\end{array}$ & $\begin{array}{l}\text { Los datos } \\
\text { muestran similitud } \\
\text { en los análisis y } \\
\text { es notable la } \\
\text { relación a las } \\
\text { dificultades que } \\
\text { presentan los } \\
\text { estudiantes en la } \\
\text { superación del } \\
\text { obsta. } \\
\text { Epistemológico } \\
\text { de consciente } \\
\text { general con } \\
\text { respecto al tema } \\
\text { de limite. Los } \\
\text { resultados } \\
\text { tienden a la } \\
\text { misma } \\
\text { información por lo }\end{array}$ \\
\hline
\end{tabular}




\begin{tabular}{|c|c|c|c|c|}
\hline & & & $\begin{array}{l}\text { concepto y de la } \\
\text { estructura de cada } \\
\text { ítem propuesto }\end{array}$ & \begin{tabular}{|l} 
que influye en la \\
importancia de \\
mejorar los \\
contenidos y \\
estrategias de \\
enseñanza para \\
lograr la atención \\
de los estudiantes \\
con respecto al \\
tema de limite
\end{tabular} \\
\hline $\begin{array}{l}\text { CONOCIMIENTO } \\
\text { PRAGMÁTICO Y } \\
\text { UTILITARIO }\end{array}$ & $\begin{array}{l}\text { Los conceptos } \\
\text { de los } \\
\text { estudiantes no } \\
\text { difieren de } \\
\text { mayor } \\
\text { profundidad de } \\
\text { acuerdo a las } \\
\text { respuestas } \\
\text { dadas en los } \\
\text { ítems } \\
\text { relacionados } \\
\text { con el concepto } \\
\text { de limite por lo } \\
\text { que no logran } \\
\text { detallar ni } \\
\text { mencionar } \\
\text { aspectos } \\
\text { importantes a } \\
\text { la hora de dar } \\
\text { una respuesta }\end{array}$ & $\begin{array}{l}\text { En respuesta a } \\
\text { ítems relacionados } \\
\text { en la prueba } \\
\text { pianista, los } \\
\text { estudiantes } \\
\text { muestran una serie } \\
\text { de problemas a la } \\
\text { hora de definir un } \\
\text { término por lo que } \\
\text { tienden a reducir el } \\
\text { concepto por } \\
\text { utilidad }\end{array}$ & $\begin{array}{l}\text { De acuerdo a las } \\
\text { respuestas en la } \\
\text { prueba diagnóstica } \\
\text { donde se determinan } \\
\text { los niveles de } \\
\text { experiencia que } \\
\text { evalúa en que nivel se } \\
\text { encuentra cada } \\
\text { estudiante para la } \\
\text { superación de este } \\
\text { obstaculillos } \\
\text { resultados muestran } \\
\text { un bajo índice de } \\
\text { superación optima al } \\
\text { obstáculo por utilidad } \\
\text { que hace que caigan } \\
\text { en repetidos errores }\end{array}$ & \begin{tabular}{|l} 
Los datos \\
muestran similitud \\
en los análisis y \\
es notable la \\
relación a las \\
dificultades que \\
presentan los \\
estudiantes en la \\
superación del \\
obsta. \\
Epistemológico \\
de consciente \\
general con \\
respecto al tema \\
de limite. Los \\
resultados \\
tienden a la \\
misma \\
información por lo \\
que influye en la \\
necesidad \\
implementar \\
nuevos métodos \\
de enseñanza \\
significativa para \\
que hayan
\end{tabular} \\
\hline
\end{tabular}




\begin{tabular}{|c|c|c|c|c|c|}
\hline & & & & & $\begin{array}{l}\text { resultados } \\
\text { óptimos y se logre } \\
\text { la superación del } \\
\text { obstáculo }\end{array}$ \\
\hline \multirow[t]{2}{*}{ 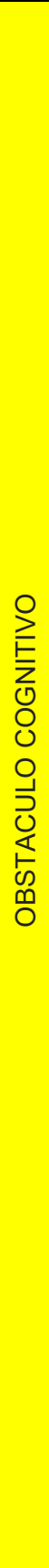 } & $\begin{array}{l}\text { OBSTACULO } \\
\text { BASADO EN LA } \\
\text { SECUENCIA DE } \\
\text { UN TEMA }\end{array}$ & $\begin{array}{l}\text { De acuerdo a } \\
\text { las respuestas } \\
\text { de los } \\
\text { estudiantes en } \\
\text { ítems } \\
\text { relacionados } \\
\text { con el grado de } \\
\text { complejidad del } \\
\text { concepto de } \\
\text { limite en cuanto } \\
\text { a ejercicios } \\
\text { propuesto no } \\
\text { difieren de } \\
\text { manera óptima } \\
\text { puesto que no } \\
\text { logran } \\
\text { familiarizarse } \\
\text { por completo } \\
\text { con el tema } \\
\text { puesto que no } \\
\text { muestran de } \\
\text { forma } \\
\text { ordenada sus } \\
\text { ideas }\end{array}$ & $\begin{array}{l}\text { De acuerdo a las } \\
\text { respuestas de los } \\
\text { estudiantes no } \\
\text { logran superar de } \\
\text { manera efectiva } \\
\text { hacia los siguientes } \\
\text { temas puesto que } \\
\text { presentan muchos } \\
\text { distractores que } \\
\text { difieren del bajo } \\
\text { manejo que tiene } \\
\text { con respecto al } \\
\text { tema }\end{array}$ & $\begin{array}{l}\text { De acuerdo a las } \\
\text { respuestas en la } \\
\text { prueba diagnóstica } \\
\text { donde se determinan } \\
\text { los niveles de } \\
\text { experiencia que } \\
\text { evalúa en qué nivel se } \\
\text { encuentra cada } \\
\text { estudiante para la } \\
\text { superación de este } \\
\text { obstaculillos } \\
\text { resultados se } \\
\text { muestran en } \\
\text { concordancia con } \\
\text { muchas de las } \\
\text { respuesta anteriores } \\
\text { puesto que no logran } \\
\text { superar de manera } \\
\text { óptima los temas }\end{array}$ & $\begin{array}{l}\text { Los datos } \\
\text { muestran similitud } \\
\text { en los análisis y } \\
\text { es notable la } \\
\text { relación a las } \\
\text { dificultades que } \\
\text { presentan los } \\
\text { estudiantes en la } \\
\text { superación del } \\
\text { obsta. } \\
\text { Epistemológico } \\
\text { de consciente } \\
\text { general con } \\
\text { respecto al tema } \\
\text { de limite. Los } \\
\text { resultados } \\
\text { tienden a la } \\
\text { misma } \\
\text { información por lo } \\
\text { que influye en la } \\
\text { necesidad hacer } \\
\text { mejoras en } \\
\text { cuanto al método } \\
\text { de explicación de } \\
\text { cada tema }\end{array}$ \\
\hline & $\begin{array}{l}\text { OBSTACULOS } \\
\text { BASADOS } \\
\text { SOBRE CASOS } \\
\text { SIMPLES }\end{array}$ & $\begin{array}{l}\text { El avance de } \\
\text { los estudiantes } \\
\text { que obtienen } \\
\text { en cada ítem } \\
\text { no demuestran } \\
\text { ir completo } \\
\text { resultados } \\
\text { efectivos ya }\end{array}$ & $\begin{array}{l}\text { Las respuestas de } \\
\text { los estudiantes en } \\
\text { cuanto a la prueba } \\
\text { diagnóstica difieren } \\
\text { que no logran pasar } \\
\text { o identificar los } \\
\text { casos simples y } \\
\text { tienden a mostrar }\end{array}$ & $\begin{array}{l}\text { De acuerdo a las } \\
\text { respuestas en la } \\
\text { prueba diagnóstica } \\
\text { donde se determinan } \\
\text { los niveles de } \\
\text { experiencia que } \\
\text { evalúa en qué nivel se } \\
\text { encuentra cada }\end{array}$ & $\begin{array}{l}\text { Los datos } \\
\text { muestran similitud } \\
\text { en los análisis y } \\
\text { es notable la } \\
\text { relación a las } \\
\text { dificultades que } \\
\text { presentan los } \\
\text { estudiantes en la }\end{array}$ \\
\hline
\end{tabular}




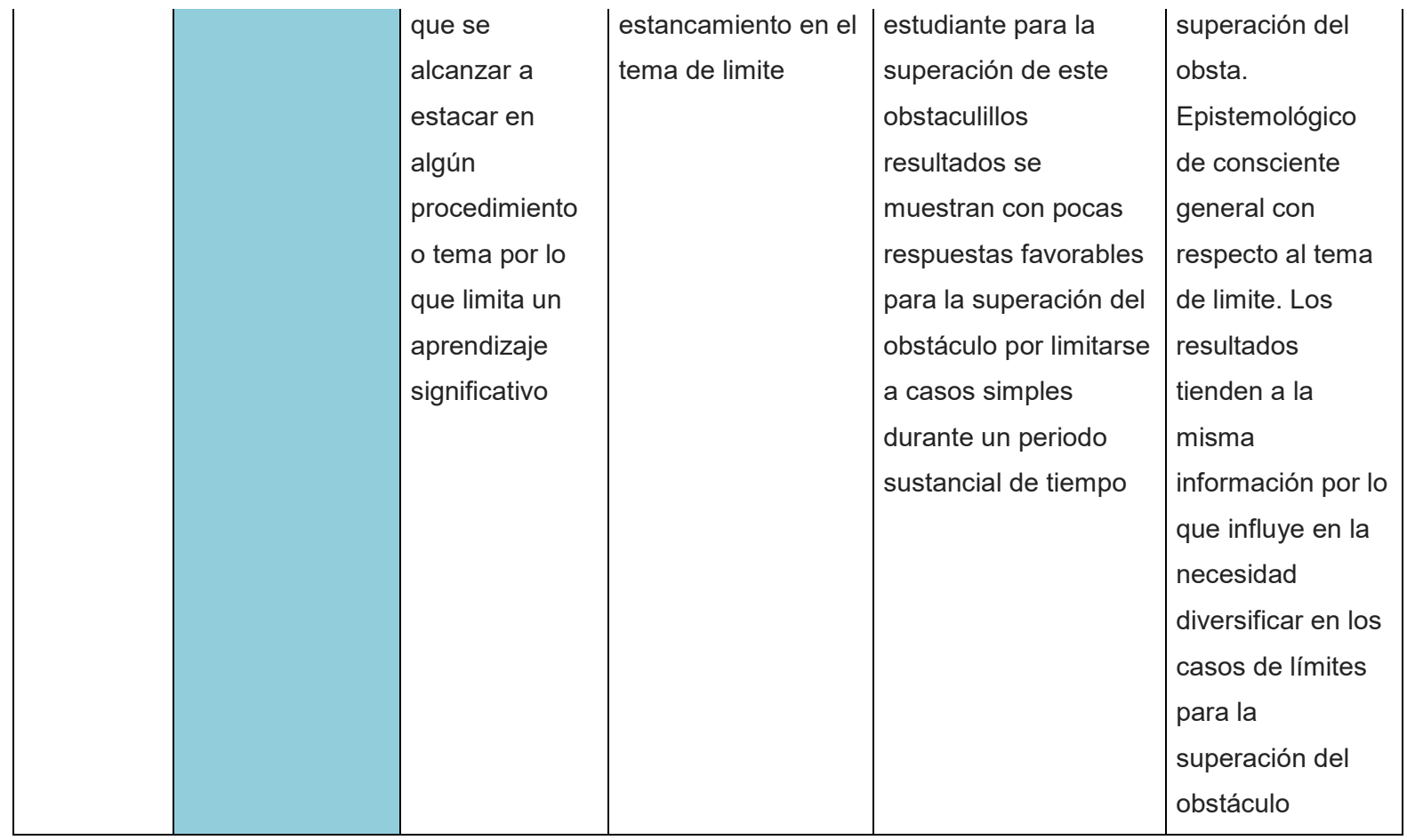

\section{CONCLUSIONES}

De acuerdo al objetivo general de la investigación y el análisis e interpretación de los resultados arrojados por las técnicas utilizadas, se puede evidenciar que los estudiantes de cálculo diferencial de una y varias variables presentan diferentes obstáculos epistemológicos y cognitivos al resolver situaciones problemas con límites, en donde se reconoce que los más frecuentes son los asociados a los conocimientos previos que son un conjunto de ideas muy propias acerca del tema y en los resultados estas ideas no son del todo profundas o significativas, el obstáculo verbal que se presenta cuando mediante una sola palabra o una imagen se tiende a dar un significado por lo que los resultados en general fueron poco favorables para explicar un concepto y dar respuesta; en el caso de obstáculo basado sobre casos simples y el obstáculo basado en la secuencia de un tema en que a medida que el curso va pasando de casos simples a complejos aumentan los vacíos conceptuales lo que ratifica que es preciso familiarizarse con el tema en un cierto orden.

En el análisis, se puede identificar que a los estudiantes se les dificulta dar una explicación con sus propias palabras sobre los conceptos

destacados en el tema de límite necesarios para la comprensión y realización de situaciones problemas. Esto es porque ellos no logran entenderlos con claridad, lo que se refleja al momento de identificar por medio de una gráfica si el límite existe o cuando se le pide que plasme la definición formal del límite de forma simbólica y que complete el significado de manera intuitiva no logran asimilar de manera que puedan generar los resultados deseas y de ahí parte la mayoría de los obstáculos. (Mora Zamora, 2002)

Teniendo en cuenta lo anterior, en la prueba diagnóstica y en la entrevista los estudiantes 1, 2 y 3 utilizan de forma inadecuada el conocimiento, dando paso a los caminos de la no superación de los obstáculos epistemológicos y cognitivos por lo que muestra causas de estancamiento y hasta de retroceso, es ahí donde se debe discernir 
causas de inercia dando paso a los caminos que se despliegan de los errores cometidos por los mismos, tales como lo son las nociones inadecuadas o conceptos previos (Bachelard, 1976), el resultado de procedimientos que son incorrectos por lo que preocupa las dificultades cognitivas que presentan los alumnos ya que en general, no lograron el desarrollo del razonamiento formal requerido para comprender los conceptos de límite.

En concordancia, los resultados obtenidos carecen de pocas diferencias por lo que sus análisis son muy parecidos puesto que los estudiantes confunden las nociones y no logran asimilar las terminologías que se utilizan, presentan con frecuencia errores donde una inadecuada lectura o escritura los llevan a generar respuestas incorrectas a los problemas planteados y debido a esto se evidencia que sus casusas son provocadas por los contenidos matemáticos, por la falta de dominio de éstos y los anteriores y por dificultades con respecto a la mala estructuración de actividades que no resultan significativas y hace que el conocimiento aprendido lo usen mal.

\section{REFERENCIAS BIBLIOGRÁFICAS}

Alfonzo, N. (2012). Técnicas E Instrumentos De Recolección De Datos Cualitativos.

Álvarez, C. (2012). La Elección Del Estudio De Caso En Investigación Educativa. Gazeta De Antroplogía, 1-13.

Bachelard, G. (1976). La Formación Del Espíritu Científico. 5 Ed. México: Siglo Veintiuno. Editores, S.A, 66.

Barrantes, H. (2006). Los Obstáculos Epistemológicos1.

Fernández March, A. (2010). La Evaluación Orientada Al Aprendizaje En Un Modelo De Formación Por Competencias En La Educación Universitaria. Revista De Docencia Universitaria,
Vol.8 (N.1) 11-34, 11-34.

Garcia Muñoz, T. (2003). El Cuestionario Como Instrumento De Investigacion/Evalucion .

Hernández Sampieri, R. (2014). Metodlogia De La Investigacion, Sexta Edicio.

Hernández Sampieri, R. (2014). Metodolodía De La Investigación (6ta. Ed.). México : Interamericana Editores.

Kazez, R. (2009). Los Estudios De Casos Y El Problema De La Selección De La Muestra, Aportes Del Sistema De Matrices De Datos.

Mora Zamora, A. (2002). Obstáculos Epistemológicos Que Afectan El Proceso De Construcción De Conceptos Del Área De Ciencias En Niños De Edad Escolar. Revista De Las Sedes Regionales, Vol. lii, Núm. 5, Mayo, , 75-89.

Salinas, P., \& Alanís, J. A. (2009). Hacia Un Nuevo Paradigma En La Enseñanza Del Cálculo Dentro De Una Institución Educativa. Revista Latinoamericana De Investigación En Matemática Educativa, Relime Vol.12 No.3 México.

Tall, D. (1989). Different Cognitive Obstacles In A Technological 